DOI:

10.1038/nrg2260

\title{
MILESTONE 8
}

\section{Get out the map}

Although the existence of variable loci in human DNA had been appreciated for some time, it was not until the late 1970s and early 1980s that a way to use polymorphisms for largescale systematic mapping of human genes was proposed.

David Botstein, Raymond White, Mark Skolnick and Ronald Davis argued that a large number of DNA sequence polymorphisms must exist in the human population, and that some of these should be detectable as variants in the length of DNA fragments produced by restriction enzymes (restriction fragment-length polymorphisms or RFLPs). These RFLPs could be detected using Southern blotting experiments on human genomic DNA. Importantly, and unlike classical polymorphic antigenic and enzyme markers, these new loci could be identified in non-coding regions of the genome as well as within genes. Linkage relationships among RFLPs could be established using pedigrees, and genetic linkage to a locus of interest would allow a gene to be mapped and defined, even if the RFLPs were not in the gene. Botstein and colleagues estimated that at least 150 highly polymorphic regions at regular intervals in the human genome would make it feasible to construct a human genetic-linkage map and to localize disease genes.

The first practical demonstration of this came in 1983 with the

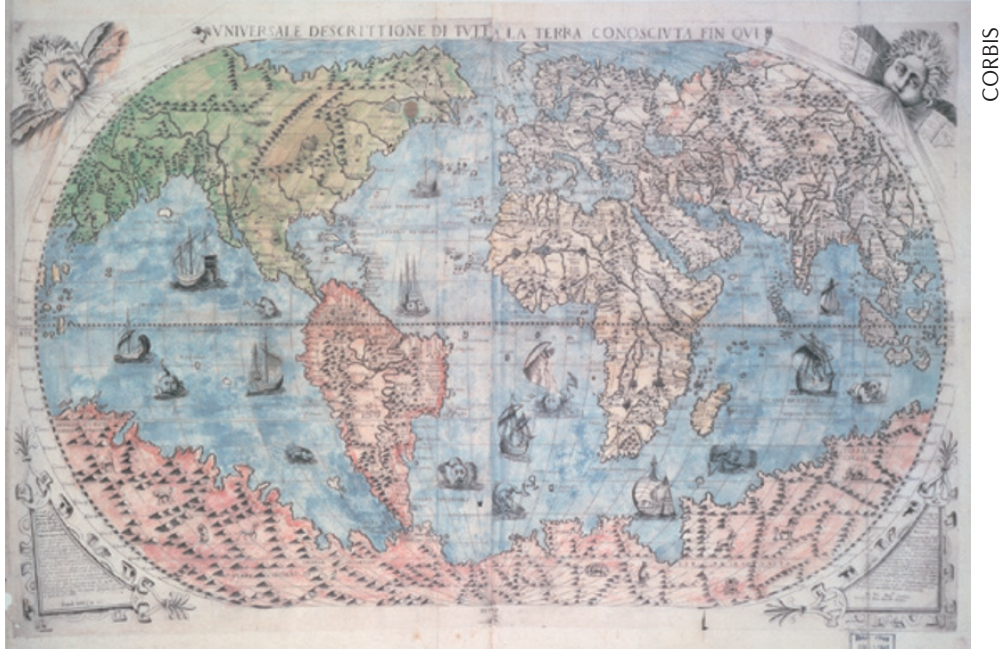

mapping of the gene for Huntington disease. As proposed by Botstein and colleagues, a large number of recombinant DNA probes defining RFLPs in human DNA had by then been identified. In a collaborative effort involving researchers in the United States and Venezuela, James Gusella and colleagues screened the DNA of members of two Huntington families with 12 such probes, and identified one that defined a marker on chromosome 4 with close linkage to the disease locus.

A new field, positional cloning of genetic disease loci, was born. RFLPs were later involved in the mapping and positional cloning of the cystic fibrosis gene by John Riordan and colleagues. Early linkage studies with RFLPs also allowed the creation of the first genome-wide genetic maps, which, together with sequencetagged sites introduced by Maynard Olson and colleagues, allowed the construction of sequence-based physical maps of genomes.

Natalie de Souza, Associate Editor, Nature Methods

ORIGINAL RESEARCH PAPERS Botstein,

D., White, R. L., Skolnick, M. \& Davis, R. W. Construction of a genetic linkage map in man using restriction fragment length polymorphisms. Am. J. Hum. Genet. 32, 314-331 (1980) | Gusella, J. F. et al. A polymorphic DNA marker genetically linked to Huntington's disease. Nature 306, 234-238 (1983) FURTHER READING Riordan, J. R. et al. Identification of the cystic fibrosis gene: cloning and characterization of complementary DNA. Science 245, 1066-1073 (1989) | Olson, M., Hood, L., Cantor, C. \& Botstein, D. A common language for physical mapping of the human genome. Science 245, 1434-1435 (1989) 